\title{
Neural Basis of Identity Information Extraction from Noisy Face Images
}

\author{
Petra Hermann, ${ }^{1,2}$ Éva M. Bankó, ${ }^{1}$ Viktor Gál, ${ }^{1,3}$ and Zoltán Vidnyánszky ${ }^{1,4}$ \\ ${ }^{1}$ Brain Imaging Centre, Research Centre for Natural Sciences, Hungarian Academy of Sciences, Budapest H-1117, Hungary, ${ }^{2}$ Faculty of Information \\ Technology and Bionics, Pázmány Péter Catholic University, Budapest H-1083, Hungary, ${ }^{3}$ MR Research Center, Szentágothai J. Knowledge \\ Center-Semmelweis University, Budapest H-1083, Hungary, and ${ }^{4}$ Department of Cognitive Science, Budapest University of Technology and Economics, \\ Budapest H-1111, Hungary
}

Previous research has made significant progress in identifying the neural basis of the remarkably efficient and seemingly effortless face perception in humans. However, the neural processes that enable the extraction of facial information under challenging conditions when face images are noisy and deteriorated remains poorly understood. Here we investigated the neural processes underlying the extraction of identity information from noisy face images using fMRI. For each participant, we measured (1) face-identity discrimination performance outside the scanner, (2) visual cortical fMRI responses for intact and phase-randomized face stimuli, and (3) intrinsic functional connectivity using resting-state fMRI. Our whole-brain analysis showed that the presence of noise led to reduced and increased fMRI responses in the mid-fusiform gyrus and the lateral occipital cortex, respectively. Furthermore, the noise-induced modulation of the fMRI responses in the right face-selective fusiform face area (FFA) was closely associated with individual differences in the identity discrimination performance of noisy faces: smaller decrease of the fMRI responses was accompanied by better identity discrimination. The results also revealed that the strength of the intrinsic functional connectivity within the visual cortical network composed of bilateral FFA and bilateral object-selective lateral occipital cortex (LOC) predicted the participants' ability to discriminate the identity of noisy face images. These results imply that perception of facial identity in the case of noisy face images is subserved by neural computations within the right FFA as well as a re-entrant processing loop involving bilateral FFA and LOC.

Key words: fusiform face area; lateral occipital cortex; resting-state fMRI

\section{Introduction}

Experimental and modeling results suggest that face perception involves an initial, fast categorization of the visual stimulus as a face (Hochstein and Ahissar, 2002; Liu et al., 2002; Lewis and Edmonds, 2003; Rousselet et al., 2003; DiCarlo and Cox, 2007; Hegdé, 2008; Crouzet et al., 2010; Cauchoix et al., 2014) and it is based primarily on the neural processes in a face-sensitive region in the fusiform gyrus, the fusiform face area (FFA; Kanwisher et al., 1997; Rossion et al., 2003, 2012; Rossion, 2008; Goffaux et al., 2011; Jiang et al., 2011). This early global and coarse face representation is subsequently refined through a re-entrant neural processing loop between the FFA and lower level visual cortical areas of the inferior and lateral occipital cortex (Rossion et al., 2003; Rotshtein et al., 2007b; Rossion, 2008; Steeves et al., 2009;

\footnotetext{
Received Aug. 25, 2014; revised March 28, 2015; accepted March 31, 2015.

Author contributions: P.H. and Z.V. designed research; P.H. and E.M.B. performed research; P.H., V.G., and Z.V. analyzed data; P.H. and Z.V. wrote the paper.

This work was supported by a grant from the Hungarian Brain Research Program (KTIA_13_NAP-A-I/18) to Zoltán Vidnyánszky. We thank Balázs Knakker and Béla Weiss for helpful comments on this manuscript and István Kóbor for help with data acquisition.

The authors declare no competing financial interests.

Correspondence should be addressed to either Zoltán Vidnyánszky or Petra Hermann, Brain Imaging Centre, Research Centre for Natural Sciences, Hungarian Academy of Sciences, Magyar tudósok körútja 2., 1117 Budapest, Hungary, E-mail: vidnyanszky.zoltan@ttk.mta.hu or hermann.petra@ttk.mta.hu.

DOI:10.1523/JNEUROSCI.3572-14.2015

Copyright $\odot 2015$ the authors $\quad 0270-6474 / 15 / 357165-09 \$ 15.00 / 0$
}

Pitcher et al., 2010; Tang et al., 2014). Specifically, in the case of phase-randomized face images, it has been suggested (Bankó et al., 2011, 2013) that the increased processing demand due to the distorted spatial localization of the facial features might lead to the engagement of a re-entrant processing loop involving the FFA and a region of the lateral occipital cortex (LOC), which represents shape information within a spatial coordinate system (Larsson and Heeger, 2006; Silson et al., 2013) and shows increased fMRI responses to noisy face images (Bankó et al., 2011). However, an important question that remains to be explored is whether it is the FFA or the LOC on whose neural representations the perception of deteriorated and noisy face images is based. Even though combined behavioral and neuroimaging results provided strong evidence for a close link between face perception and the neural processes in the FFA in the case of intact face images (Grill-Spector et al., 2004; Yovel and Kanwisher, 2005; Furl et al., 2011; Huang et al., 2014), it has not been investigated whether this holds true also for faces that are noisy and poorly visible.

To address this question, we measured face-identity discrimination performance and fMRI responses in the FFA and LOC in the cases of both intact and phase-randomized face stimuli. To examine whether the individual differences in the discrimination of the identity of noisy face stimuli are associated with the noiseinduced modulation of fMRI responses in the FFA or in the LOC, 
we computed correlations between these behavioral and neural measures. Furthermore, based on the suggested role of the re-entrant neural mechanisms in the processing of noisy faces, we predicted that the individual ability to handle stimulus noise might depend on the strength of functional interactions between FFA and LOC. To test this prediction, we estimated the strength of intrinsic functional connectivity between bilateral FFA and LOC using resting-state fMRI (Biswal et al., 1995; Fox et al., 2005; for review, see Fox and Raichle, 2007) and computed correlations between these measures and the noisy face-identity discrimination performance.

\section{Materials and Methods}
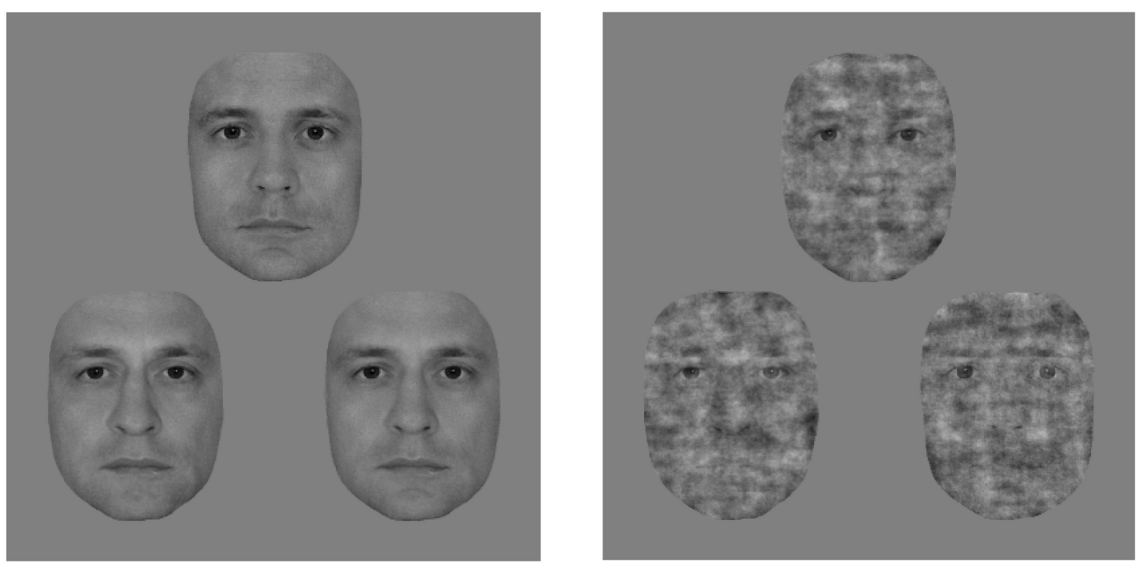

Figure 1. Stimuli of the psychophysics experiment. Exemplar face triplet for the intact (left) and the $55 \%$ phase noise (right) stimulus condition presented in the $3 \mathrm{AFC}$ identity-discrimination task.

\section{Subjects}

Altogether 26 Caucasian subjects ( 15 male, one left-handed, mean \pm SD; age: $27 \pm 6$ years) participated in the experiment and gave informed written consent in accordance with the protocols approved by the ethics committee of Semmelweis University, Budapest, Hungary. None of them had any history of neurological or psychiatric diseases, and all had normal or corrected-to-normal visual acuity.

\section{Psychophysics experiment}

Stimuli. In the psychophysics experiment, trials consisted of triplets of morphed male face images. Front-view grayscale images of male faces with neutral expressions were cropped to eliminate external features (hair, etc.) and were equated for luminance and contrast. Triplets were obtained by first pairing two individuals and creating a linear morph continuum using a warping algorithm (JPsychomorph; Tiddeman et al., 2001). Altogether 78 continua were created from 13 individuals. Triplet members were selected from these continua as follows: face $\mathrm{A}$ and $\mathrm{C}$ were chosen to be the $20 / 80 \%$ and $80 / 20 \%$ points, respectively, while face $\mathrm{B}$ was taken from in between, such that the morph distance between the oddball image (e.g., A) and its neighbor (B) was larger than the distance between the other two images (e.g., B and C). These distances were based on pilot measurements to keep performance within the $65-75 \%$ range and they differed between face conditions. The following $2 \times 2$ conditions were used. Faces with $100 \%$ phase coherence were presented in the intact face condition, and for the noisy face condition the phase coherence was decreased to $45 \%$ (55\% noise; Fig. 1). Phase coherence was manipulated using custom-made scripts based on the weighted mean phase technique (Dakin et al., 2002). Both intact and noisy faces were presented upright and upside down. In the current study, however, we present and discuss only the results obtained with upright stimuli, while results obtained with inverted faces will be presented elsewhere.

Triplets were displayed at the center of the screen on a uniform gray background in a regular triangular arrangement with $4^{\circ}$ eccentricity. Triplets measured $\sim 11 \times 12^{\circ}$, faces subtending $4.5 \times 6.0^{\circ}$ each, and were presented on a 26" LG IPS LCD monitor at a refresh rate of $60 \mathrm{~Hz}$ viewed from $50 \mathrm{~cm}$. Stimulus presentation was controlled by MATLAB 7.1. (The MathWorks) using the Psychophysics Toolbox Version 3 (PTB-3; Brainard, 1997; Pelli, 1997; http://psychtoolbox.org/).

Experimental procedure. In the psychophysics experiment, participants performed a three-alternative forced-choice (3AFC) identity finediscrimination task. Subjects were required to select the face that differed the most from the other two (i.e., oddball face, either A or C). Before the experiment, each subject was given a practice session to get familiar with the task. Each trial began with a cue $\left(1^{\circ}\right)$ appearing just above fixation for $100 \mathrm{~ms}$, indicating the orientation of the upcoming stimuli (upright or inverted). Triplets were presented without a fixation dot under freeviewing conditions until subjects responded, but they were terminated at $5000 \mathrm{~ms}$ if no response was made. Trials were separated by an intertrial interval, which varied randomly between 900 and $1100 \mathrm{~ms}$, with only the fixation dot present. Oddball faces appeared with equal probability in each of the three possible spatial positions. Each unique face triplet was presented only once per condition, randomly assigned to one of the five runs for each participant. Within a single run, the $2 \times 2$ conditions (intact/noise and upright/inverted) were intermixed and presented in random order. Each participant completed five runs, yielding 65 trials altogether for each condition.

\section{fMRI experiment}

Stimuli. During the block-design fMRI scanning session, images of human faces and common objects were presented. Face stimuli consisted of front-view grayscale photographs of four male faces with neutral, happy, and fearful expressions preprocessed similarly to the images used in the psychophysics experiment. They were presented either with 100\% phase coherence (intact face condition) or manipulated by decreasing their phase coherence to $45 \%$ (55\% noise; noisy face condition) using the weighted mean phase technique (Dakin et al., 2002). Object stimuli consisted of grayscale images of three different objects from four categories (cars, mugs, jugs, and fruits) chosen from the Amsterdam Library of Object Images database (Geusebroek et al., 2005). All images were equated for luminance and contrast and presented centrally, subtending $4.5 \times 6.0^{\circ}$, on a uniform gray background. Stimuli were projected onto a translucent screen located at the back of the scanner bore using a Panasonic PT-D3500E DLP projector (Matsushita Electric Industrial) at a refresh rate of $60 \mathrm{~Hz}$, and they were viewed through a mirror attached to the head coil at a viewing distance of $57 \mathrm{~cm}$. Head motion was minimized using foam padding. Stimulus presentation was controlled by MATLAB 7.1. (The MathWorks) using PTB-3 (Brainard, 1997; Pelli, 1997; http://psychtoolbox.org/).

Experimental procedure. The fMRI session included two block-design runs. In each run, $16 \mathrm{~s}$ long blocks of intact faces (IF), noisy faces (NF), and objects $(\mathrm{O})$ were interleaved with baseline blocks, which contained only a fixation dot. Stimuli were presented for $500 \mathrm{~ms}$ with $0.5 \mathrm{~Hz}$ frequency. A run consisted of 6 blocks of each stimulus type (IF, NF, and O) and 19 baseline blocks, making a total number of 37 blocks per run, lasting 10 min each. Subjects performed a one-back memory task and reported the total number of one-back repetitions at the end of the run. In addition to the block-design scans, participants performed an $8 \mathrm{~min}$ long resting-state run before the experimental runs. They were instructed to lie still, with their eyes closed.

\section{fMRI scanning}

Data were collected at the MR Research Center of Szentágothai Knowledge Center (Semmelweis University, Budapest, Hungary) on a 3.0 tesla Philips Achieva scanner equipped with an eight-channel SENSE head coil. High-resolution anatomical images were acquired for each subject using a T1-weighted 3D TFE sequence yielding images with $1 \times 1 \times 1$ $\mathrm{mm}$ resolution. Functional images were collected with a noninterleaved acquisition order covering the whole brain with a BOLD-sensitive $\mathrm{T}^{*}$ weighted EPI sequence. For the experimental fMRI, a total of 301 vol- 
umes were acquired using 31 transversal slices ( $4 \mathrm{~mm}$ slice thickness with $3.4 \mathrm{~mm} \times 3.4 \mathrm{~mm}$ in-plane resolution, $\mathrm{TR}=2 \mathrm{~s}, \mathrm{TE}=30 \mathrm{~ms}$ ), while for the resting-state fMRI, a total of 240 volumes were recorded using 36 transversal slices ( $4 \mathrm{~mm}$ slice thickness with $3 \mathrm{~mm} \times 3 \mathrm{~mm}$ in-plane resolution, $\mathrm{TR}=2 \mathrm{~s}, \mathrm{TE}=30 \mathrm{~ms}$ ).

\section{fMRI data analysis}

Preprocessing and analysis of the imaging data were performed using the SPM8 toolbox (Wellcome Trust Centre for Neuroimaging, University College London, UK) and custom MATLAB codes. The functional images were realigned to the first image within a session for motion correction and then spatially smoothed using an $8 \mathrm{~mm}$ full-width halfmaximum Gaussian filter. The anatomical images were coregistered to the mean functional $\mathrm{T} 2 *$ images followed by segmentation and normalization to the MNI-152 space using SPM's segmentation toolbox. The gray matter mask was used to restrict statistical analysis on the functional files. To define the regressors for the general linear model analysis of the data, a canonical hemodynamic response function was convolved with boxcar functions, representing the onsets of the experimental conditions. Movement-related variance was accounted for by the spatial parameters resulting from the motion correction procedure. A high-pass filter with a cycle cutoff of $128 \mathrm{~s}$ was also implemented in the design to remove low-frequency signals. The prepared regressors were then fitted to the observed functional time series within the cortical areas defined by the gray matter mask. The resulting individual statistical maps were then transformed to the MNI-152 space using the transformation matrices generated during the normalization of the anatomical images. The estimated $\beta$-weights of each regressor served as input for the second-level whole-brain random-effects analysis, treating subjects as random factors. For visualization purposes, the IF $>$ NF and NF $>$ IF contrasts were projected with $p_{\mathrm{FDR}}<0.05$ threshold onto the smoothed ICBM152 brain (Mazziotta et al., 1995, 2001a, b) using BrainNet Viewer (Xia et al., 2013; http://www.nitrc.org/projects/bnv/). Stereotaxic coordinates are reported in Montreal Neurological Institute (MNI) space and regional labels were derived using the AAL atlas (Tzourio-Mazoyer et al., 2002) provided with xjView 8 (http://www.alivelearn.net/xjview8/).

For the resting-state analysis, several other preprocessing steps were applied in addition to the aforementioned standard preprocessing to reduce spurious variance that is unlikely to reflect neural activity in resting-state data. These steps included voxelwise regression of the time course obtained from rigid-body head motion correction, voxelwise regression of the mean time course of whole-brain, ventricle, and white matter blood-oxygen-level-dependent (BOLD) fluctuations (Weissenbacher et al., 2009). To retain low-frequency signals only $(0.009-0.08$ $\mathrm{Hz}$; Cordes et al., 2001), we used a combination of temporal high-pass (based on the regression of ninth-order discrete cosine transform basis set) and low-pass (bidirectional 12th-order Butterworth IIR) filters.

ROI selection for correlation analysis. We conducted correlation analyses for which we determined the individual locations of three regions of interest (ROIs) [FFA, occipital face area (OFA), and LOC] to take the interindividual variability in their locations into account, which is crucial for intersubject correlations. To define them in each hemisphere and in each participant, we located the peak voxel within a region exhibiting a selective response to face (FFA and OFA) and object images (LOC). The locations of FFA and OFA were determined as the areas in the middle fusiform gyrus and inferior occipital gyrus, respectively, responding more strongly to intact faces than to objects. LOC was identified as the area on the lateral surface of the middle occipital cortex showing significantly stronger activation to objects than to intact faces. Peak voxel activity of all ROIs was required to meet a minimum threshold of $p_{\text {uncorrected }}=0.005$. With each ROI, we took the contiguous cluster of significantly activated voxels $\left(t_{(560)}>2\right)$ within a $10 \mathrm{~mm}$ radius sphere centered at the peak voxel and selected a single voxel showing the highest absolute $\beta$-difference in the intact versus noisy faces contrast. We used the $\beta$-difference (signed to reflect the direction of the contrast) obtained from this voxel to characterize the magnitude of the noise effect in each region for our correlation analysis. The defined voxel coordinates were then transformed to each subject's na-
Table 1. Peak voxel coordinates for the regions of interest (ROIs)

\begin{tabular}{lrlrlll}
\hline ROI & \multicolumn{1}{c}{$x$} & \multicolumn{3}{c}{$\begin{array}{l}\text { No. of voxels in } \\
\text { the cluster }\end{array}$} & $D$ & $N$ \\
\hline rFFA & $42 \pm 0.6$ & $-49 \pm 1.0$ & $-21 \pm 0.6$ & $253 \pm 30$ & $5.2 \pm 0.6$ & 23 \\
IFFA & $-40 \pm 0.7$ & $-49 \pm 1.3$ & $-21 \pm 0.9$ & $145 \pm 34$ & $3.5 \pm 0.6$ & 21 \\
rOFA & $41 \pm 0.7$ & $-76 \pm 1.6$ & $-15 \pm 0.6$ & $188 \pm 31$ & $5.9 \pm 0.7$ & 16 \\
rLOC & $43 \pm 1.0$ & $-78 \pm 0.8$ & $9 \pm 0.9$ & $167 \pm 24$ & $6.6 \pm 0.7$ & 18 \\
ILOC & $-41 \pm 1.0$ & $-80 \pm 0.8$ & $7 \pm 0.9$ & $229 \pm 24$ & $5.8 \pm 0.8$ & 19 \\
\hline
\end{tabular}

The MNI coordinates ( $x, y, z$ in millimeters) of the peak voxels from the IF $>0$ and $0<\mathrm{IF}$ contrasts in the case of FFA, $O F A$, and $L O C$, respectively. ROls were defined as the contiguous cluster of significantly activated voxels $\left(t_{(560)}>2\right)$ within a $10 \mathrm{~mm}$ radius sphere centered at the given peaks. Please note, that for the correlation analysis the activity of a single voxel showing the largest beta difference in the IF versus NF contrast was chosen. The distance $(D)$ of this voxel from the peak coordinate of each ROI is also shown in millimeters. Provided data are mean \pm SEM across participants $(N)$ for whom these regions were individually identifiable. Note that the OFA was reliably definable only in the right hemisphere in the majority of subjects.

tive space. We only included subjects in the analysis for whom we could individually define these ROIs (for details, see Table 1).

For visualization purposes, we generated a probability density map illustrating the spatial distribution of the highest noise effect voxels across participants in the FFA and in the LOC. The individual normalized binary masks for each ROI were first averaged across subjects to create a voxelwise probability map and then convolved it with a $9 \mathrm{~mm}$ Gaussian kernel. The kernel size was chosen based on the average distance between the selected voxels of the participants. The resulting voxel density map was superimposed onto the smoothed ICBM152 brain (Mazziotta et al., 1995, 2001a, b) using BrainNet Viewer (Xia et al., 2013; http://www.nitrc.org/projects/bnv/).

Functional connectivity analysis. To examine functional connectivity at rest, pairwise linear correlations were calculated using the extracted BOLD time course of the predefined ROIs (i.e., the voxel showing the highest noise-related modulation within the ROI) for each participant. One-sample $t$ tests were performed to determine which regions show reliable resting-state connectivity.

\section{Correlation analysis}

To test the behavioral relevance of the noise effect on the fMRI responses, we correlated the individual $\beta$-differences in the FFA, OFA, and LOC regions with subjects' discrimination performance on noisy faces. We conducted a semipartial correlation analysis to partial out the influence of the intact face performance on the noisy face accuracy to minimize the confounding effect of individual differences in the efficacy of overall face perception of the participants. Skipped Pearson's correlation coefficients were calculated with the Robust Correlation Toolbox (Pernet et al., 2012) in MATLAB. Bivariate outliers were detected using an adjusted box-plot rule and removed in the computation of skipped correlations. For correlation coefficients $(r), 95 \%$ confidence intervals (CI) were calculated based on 10,000 samples with the percentile bootstrap method implemented in the toolbox.

The relationship between individual resting-state functional connectivity coefficients (rsFC strength) and behavioral performance on noisy faces was studied by computing between-subject partial correlations using skipped Pearson's correlation, eliminating the variance related to efficacy of overall face perception both from the rsFC strength and from the noisy face perception performance. This again served to control for the individual differences in face-identity discrimination.

\section{Results}

\section{Results of the whole-brain analysis}

The whole-brain random-effects analysis of fMRI data using a $p_{\text {FDR }}<0.05$ threshold revealed that the presence of phase noise strongly affected bilateral occipitotemporal cortical processing of face images (Fig. 2). To specifically address the questions that we aimed to investigate in the current study, our analysis will be focused on two visual cortical areas: the fusiform gyrus (i.e., FFA) and the middle occipital gyrus (i.e., LOC). Noisy faces relative to intact faces led to decreased activation in the fusiform gyrus bilaterally (Fig. $2 A ; t_{(25)}=3.83 ; x, y, z=42,-44,-22$ and $t_{(25)}=$ 



Figure 2. Results of the whole-brain random-effects analysis. Bilateral areas of the fusiform gyrus showed significantly lower activation for noisy relative to intact faces $(\boldsymbol{A})$, while larger responses to noisy than intact faces were found bilaterally in the middle occipital gyrus (B). Statistical maps are displayed with $p_{\mathrm{FDR}}<0.05$ on the smoothed ICBM152 brain (Mazziotta et al., 1995,2001 , b). IFG, left fusiform gyrus; rFG, right fusiform gyrus; IMOG, left middle occipital gyrus; rMOG, right middle occipital gyrus.

$4.14 ; x, y, z=-40,-42,-20$ for the right and left hemisphere, respectively), which is in agreement with studies observing noiseinduced attenuation in the FFA responses (Heekeren et al., 2004; Horovitz et al., 2004; Righart et al., 2010). The MNI coordinates of this noise-induced modulation closely corresponds to the midfusiform face-selective region referred to as mFus-faces, also known as FFA-2 (Pinsk et al., 2009; Weiner and Grill-Spector, 2010; for review, see Grill-Spector and Weiner, 2014). In contrast, the results also revealed that there was an increased bilateral activation in the middle occipital gyrus in the noisy compared with the intact face condition (Fig. $2 B ; t_{(25)}=5.18 ; x, y, z=36$, $-82,8$ and $t_{(25)}=5.71 ; x, y, z=-34,-86,4$ for the right and left hemisphere, respectively), which is in accordance with our previous findings (Bankó et al., 2011). Based on its coordinates, this region appears to be in close correspondence with the shapeselective, retinotopically organized $\mathrm{LO} 2$ area introduced by Larsson and Heeger (2006), which is part of the LOC.

\section{Relationship between behavior and fMRI responses to noisy faces}

Participants' performance in the three-alternative forced-choice identity-discrimination task was $73.8 \pm 1.7$ and $61.9 \pm 1.7 \%$ (mean \pm SEM) in the case of intact and phase-randomized face stimuli, respectively. To investigate the relationship between the noise-induced modulation found in the fMRI responses and individual performance to noisy faces, we conducted a semipartial correlation analysis using the intact face performance as a covariate for the noisy face performance to control for the confounding effect of the overall face perception ability of the participants. Within the individually defined face-selective FFA, OFA, and object-selective LOC we selected a single voxel with the largest absolute $\beta$-difference in the intact versus noisy faces contrasts and used the signed difference to characterize the magnitude of the noise effect in these regions for each participant (for ROI definition, see Materials and Methods; Fig. 3A, Table 1). This ROI-based semipartial correlation analysis revealed that the magnitude of noise effect measured in the right FFA — as expressed by $\mathrm{fMRI}$ response reduction in the noisy relative to the control condition-negatively correlated with the behavioral accuracy in the case of noisy faces (Fig. 3B): the larger the effect of noise in the right FFA, the lower the identity discrimination performance for

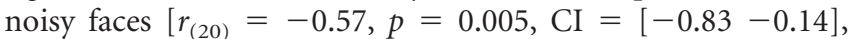
number of outliers $(\mathrm{NO})=0]$. On the other hand, we found no such correlations in the left FFA and bilateral LOC (Fig. 3B; $r_{(18)}=-0.30, p=0.183, \mathrm{CI}=[-0.670 .23], \mathrm{NO}=0 ; r_{(15)}=0.39$, $p=0.106, \mathrm{CI}=[-0.030 .71], \mathrm{NO}=0$; and $r_{(12)}=0.04, p=$ $0.897, \mathrm{CI}=[-0.490 .42], \mathrm{NO}=4$ for left FFA, right and left LOC, respectively). Note, we also failed to find significant correlation between the identity discrimination performance for noisy faces and the noise-induced fMRI response modulation in the OFA $\left(r_{(13)}=-0.36, p=0.176, \mathrm{CI}=[-0.770 .23], \mathrm{NO}=0\right)$, a region in the inferior occipital gyrus that was shown to be involved in an earlier feature-level processing stage of facial identity computations (for review, see Haxby et al., 2000; Pitcher et al., 2011b). This appears to be in agreement with the results of our wholebrain random-effects analysis showing that fMRI responses in this region are not significantly different from each other for intact and noisy face stimuli. These results indicate that identity discrimination in the case of noisy faces could be associated primarily with right FFA processes.

\section{Results of the intrinsic functional connectivity analysis}

We investigated the behavioral relevance of the functional interactions between the voxels of the FFA and LOC exhibiting the highest noise effect by examining interindividual differences in resting-state functional connectivity in relation to the observed differences in identity discrimination accuracy for noisy faces. We first tested the extent to which BOLD responses in these regions were functionally correlated at rest. Reliable connectivity strengths were found between all ROI pairs using one-sample $t$ tests $(t>2.86, p<0.01$ for all possible ROI pairs; Fig. $4 A)$. The partial correlation analysis, used to control for the influence of the overall face perception ability of the participants on $\mathrm{rsFC}$ strength and noisy face performance, revealed that the functional connectivity strength between bilateral FFA (rFFA, right FFA; IFFA, left FFA) and bilateral LOC (rLOC, right LOC; lLOC, left LOC) correlated positively with the behavioral accuracy for noisy faces (Fig. 4B): the stronger the functional connectivity between these regions during rest, the better the face-identity discrimination performance in the noisy condition (rFFA-rLOC: $r_{(12)}=0.59, p=$ $0.020, \mathrm{CI}=[0.210 .88], \mathrm{NO}=2 ; \mathrm{rFFA}-\mathrm{lLOC}: r_{(13)}=0.65, p=0.007$, $\mathrm{CI}=[0.350 .86], \mathrm{NO}=2$; lFFA-rLOC: $r_{(11)}=0.69, p=0.006, \mathrm{CI}=$ $[0.510 .91], \mathrm{NO}=2$; and IFFA-ILOC: $r_{(13)}=0.68, p=0.004, \mathrm{CI}=[0.42$ 0.87 , $\mathrm{NO}=1$ ). Performance for noisy faces also correlated positively with the connectivity strength between the right and left FFA $\left(r_{(17)}=0.59, p=0.006, \mathrm{CI}=\left[\begin{array}{ll}0.17 & 0.92\end{array}\right], \mathrm{NO}=1\right)$. On the other hand, similar relationship was not detectable in the case 
A



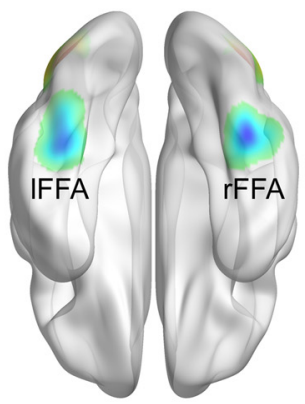

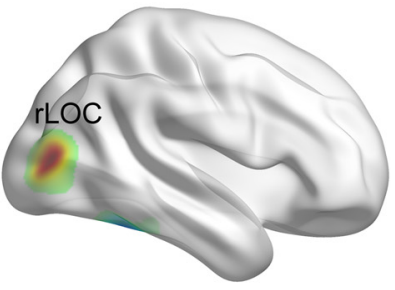

probability density

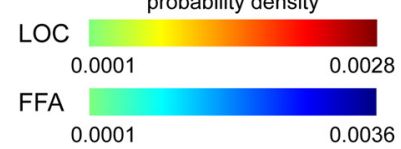

B
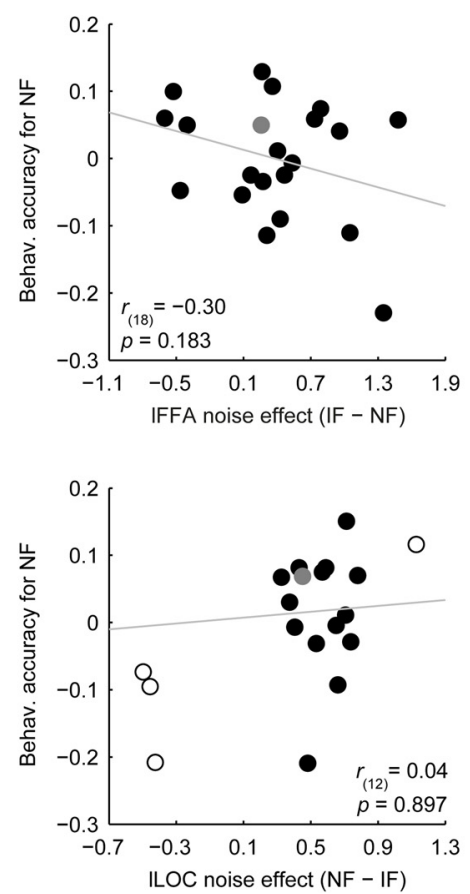


Figure 3. Results of the ROI-based correlation analysis. $\boldsymbol{A}$, Probability density map illustrating the spatial distribution of the highest noise-effect voxels across participants in bilateral FFA and LOC. Color scales reflect probability density estimates (cool colors, FFA; warm colors, $\mathrm{LOC}$ ). $B$, Relationship between the noise-induced modulation of the $\mathrm{FMRI}$ responses and the behavioral accuracy in discriminating noisy faces: smaller decrease of the $\mathrm{fMRI}$ responses in the right FFA indicated better identity discrimination. Due to the semipartial correlation procedure (see Materials and Methods, Correlation analysis), correlation scatter plots depict residual values on the $y$-axis. The $y$-axis values denote behavioral accuracy for noisy faces indexed by the residual correct response ratio. The $x$-axis values denote noise effect on the fMRI responses indexed by the $\beta$-difference in the IF versus NF contrast. Circles represent individual participants and bivariate outliers are marked with open circles, while the data point for the lefthanded subject is depicted in gray. Diagonal line indicates linear least-squares fit.

of the right and left LOC $\left(r_{(14)}=-0.05, p=0.841, \mathrm{CI}=\right.$ $\left[\begin{array}{ll}-0.53 & 0.48\end{array}\right], \mathrm{NO}=0$ ).

Since previous research has shown that resting-state functional connectivity between the FFA and OFA is associated with identity perception in the case of intact faces (Zhu et al., 2011), we also tested the relation between the strength of the FFA-OFA intrinsic functional connectivity and identity-discrimination performance for noisy faces. Although in accordance with previous results (Zhang et al., 2009; Zhu et al., 2011; O'Neil et al., 2014) we found a pronounced resting-state connectivity between the FFA and OFA $\left(t_{(15)}=6.27, p<0.001\right.$ and $t_{(13)}=4.57, p<0.001$ for rFFA-rOFA and IFFA-rOFA, respectively), its strength was not correlated with the noisy face identification performance $\left(r_{(13)}=-0.16, p=0.566, \mathrm{CI}=[-0.63\right.$ $0.59], \mathrm{NO}=0$ and $r_{(10)}=0.28, p=0.350$, $\mathrm{CI}=\left[\begin{array}{ll}-0.24 & 0.70\end{array}\right], \mathrm{NO}=1$ for rFFArOFA and IFFA-rOFA, respectively). In sum, these results suggest that faceidentity perception in the case of noisy faces is based on functional interactions between bilateral FFA and LOC.

\section{Discussion}

We have found that adding phase noise to face images leads to reduced and increased fMRI responses to faces in bilateral mid-fusiform gyrus and bilateral LOC, respectively, which is in agreement with previous results (Heekeren et al., 2004; Bankó et al., 2011). Importantly, our results provide the first evidence that only in the right face-selective FFA did noise-induced modulation of the fMRI responses show a close association with the individual differences in face-identity discrimination performance of noisy faces: smaller decrease of the fMRI responses was associated with better identity discrimination. This implies that the perception of noisy face images is based on the neural representations extracted from the right FFA. Furthermore, our results also revealed that the strength of intrinsic functional connectivity within the visual cortical network composed of bilateral FFA and bilateral object-selective LOC predicts the participants' ability to discriminate the identity of noisy face images.

Our results are in agreement with previous findings showing that representations extracted by the FFA embody the primary neural substrate of facial identity perception in the case of intact faces. It was found that fMRI responses in the FFA are closely associated with successful identification of faces but not nonface objects (Grill-Spector et al., 2004), as well as with the well known marker of facespecific processing, the behavioral faceinversion effect (Yovel and Kanwisher, 2005). Based on its coordinates, the FFA subregion whose fMRI responses were associated with noisy face-identity discrimination in our study appears to be in close correspondence with the face-selective region related to intact face perception in the mid-fusiform gyrus (Grill-Spector et al., 2004; Yovel and Kanwisher, 2005; Huang et al., 2014). This anterior part of the FFA, referred to as mFus-faces (Weiner and Grill-Spector, 2010; for review, see Grill-Spector and Weiner, 2014), shows greater fMRI adaptation to repeated face images than the more posterior pFusfaces (Weiner et al., 2010), suggesting its pivotal role in identity perception.

It is important to note that previous results concerning the role of FFA in identity perception in the case of faces with deteriorated facial information were ambiguous. On the one hand, it 


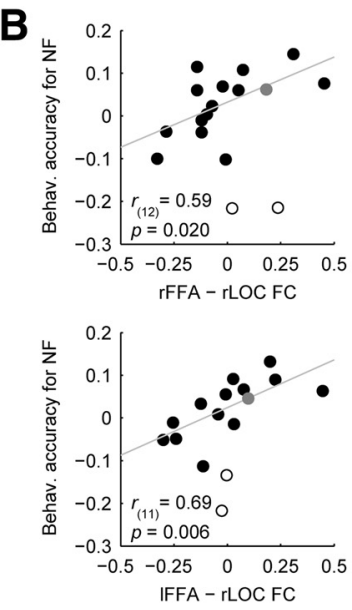
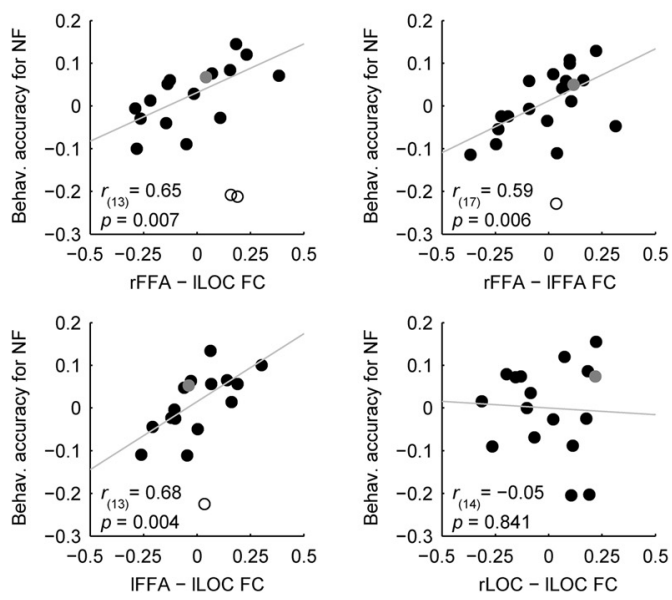

Figure 4. Results of the intrinsic functional connectivity analysis. $A$, Connections between the pairs of ROIs displayed as edges and overlaid on the probability density map from Figure $3 A$. The thickness of an edge represents the strength of the connection [correlation coefficients ( $r$ ) averaged across subjects]; significant correlations were found between all ROI pairs investigated. $\boldsymbol{B}$, Scatter plots indicating the relationship between the intrinsic functional connectivity and the behavioral accuracy for noisy faces. The strength of the functional connectivity between bilateral FFA and LOC, as well as between the right and left FFA, correlated positively with the identity-discrimination performance in the case of noisy faces. Due to the partial correlation procedure (see Materials and Methods, Correlation analysis), correlation scatter plots depict residual values on both axes. The $y$-axis values denote the behavioral accuracy for noisy faces indexed by the residual correct response ratio. The $x$-axis values denote the connection strength between a ROI pair indexed by the residual correlation coefficient. Circles represent individual participants. Bivariate outliers are marked with open circles, while the data point for the left-handed subject is depicted in gray. Diagonal line indicates linear least-squares fit. $\mathrm{FC}$, functional connectivity $\left({ }^{* *} p<0.01,{ }^{* * *} p<0.001\right)$.

has been shown that scrambling or adding noise to face images leads to reduced fMRI responses in the FFA (Lerner et al., 2001; Heekeren et al., 2004; Horovitz et al., 2004; Righart et al., 2010), which is in accord with a large body of neuroimaging results showing that the presence of noise in images strongly attenuates feature/object-selective visual cortical responses in the downstream, higher level object-processing areas (Grill-Spector et al., 1998; Lerner et al., 2001; Rainer et al., 2001, 2002; Tjan et al., 2006). Based on these findings, facial feature processing in the FFA was expected to be impaired in the presence of noise. On the other hand, involvement of the FFA in the processing of noisy faces is implicated by the results of a recent study, in which no response reduction was found in the FFA as a result of adding phase noise to the face images (Bankó et al., 2011). Furthermore, it has also been shown that face-sensitive responses emerge first in the FFA when participants perform a face-detection task in a paradigm where scenes containing faces are revealed gradually from visual noise (Jiang et al., 2011). Considering the difference in task conditions between these studies might help to reconcile the apparent discrepancies in the obtained results. In studies where fMRI responses in the FFA were found to decrease as a result of noise, data were acquired during either passive viewing or under task conditions where fine facial information was irrelevant (Heekeren et al., 2004; Horovitz et al., 2004; Righart et al., 2010). Whereas, in the Bankó et al. (2011) study, where noise effects were absent in the FFA, participants performed a highly demanding face-gender categorization task. As visual attention and task demands strongly affect fMRI responses in the FFA (Clark et al., 1997; Wojciulik et al., 1998; O'Craven et al., 1999; Reddy et al., 2007; Righart et al., 2010), it is reasonable to assume that the enhancing effects of top-down attention in the Bankó et al. (2011) study could have masked the noise-induced reduction of the FFA responses. This interpretation is in accordance with the results of a previous study (Kayser et al., 2010) showing that decreasing motion coherence (i.e., making the stimulus noisier) leads to decreased MT+ responses only when the motion stimulus is task-irrelevant/unattended. In contrast, when motion is attended the effect of decreasing motion coherence disappeared or even reversed, leading to larger MT + responses. Our present results are also in line with this account as using noisy face stimuli we obtained noise-induced reduction of the fMRI responses in the FFA under moderately demanding task conditions.

Our findings also shed light on the visual cortical network that enables the extraction of identity information when stimuli are noisy, i.e., with deteriorated facial information. Previous research has shown that adding phase noise to the stimuli leads to increased fMRI responses in a region of bilateral LOC (Bankó et al., 2011), whose coordinates closely correspond to the shapeselective, retinotopically organized LO2 area, which represents shape information within a spatial coordinate system (Larsson and Heeger, 2006; Silson et al., 2013). Based on these findings, we hypothesized that increased processing demands due to the distorted spatial localization of the facial features in the case of phase-randomized face images might trigger re-entrant processing mechanisms involving the LOC. Our intrinsic functional connectivity analysis provides the first direct evidence that this might indeed be the case, showing that the strength of the functional connectivity between bilateral LOC and FFA predicts the participants' ability to discriminate the identity of noisy face images. Although LOC is considered primarily as an objectselective area (Malach et al., 1995; Grill-Spector et al., 2001; Hasson et al., 2003), it shows elevated activation for faces as well, especially for inverted ones (Yovel and Kanwisher, 2005; Epstein et al., 2006; Gilaie-Dotan et al., 2010). There is also evidence showing that the LOC is essentially involved in the feature-based processing of face images (Lerner et al., 2001; Yovel and Kanwisher, 2004; Rotshtein et al., 2007a; Pitcher et al., 2011a; Zhang et al., 2012) and its activation might contribute to better behavioral performance in face perception (Zhang et al., 2012). These findings provide support for our results showing that LOC processes are engaged in the extraction of face-identity information for stimuli with deteriorated facial information.

Our resting-state connectivity analysis also revealed that functional connectivity between the left and right FFA was also closely associated with the identity discrimination performance for faces embedded in noise. This is in agreement with the results of nu- 
merous previous studies showing that despite the right hemisphere dominance for face perception (Kanwisher et al., 1997; McCarthy et al., 1997; Yovel et al., 2008; Rossion et al., 2012), interhemispheric interactions appear to be necessary for successful face recognition. The strong task-related (Minnebusch et al., 2009; Zhen et al., 2013), background (Davies-Thompson and Andrews, 2012), and resting-state (Zhang et al., 2009) functional connectivity between corresponding face regions in the two hemispheres (including the right and left FFA) suggests that face processing involves a bilateral network. Furthermore, it was also shown that bilateral presentation of face stimuli leads to improved performance compared with unilateral presentation (Mohr et al., 2002; Schweinberger et al., 2003; Reinholz and Pollmann, 2007; Baird and Burton, 2008). Thus, there is converging evidence that left FFA mechanisms, mainly associated with featural processing (Rossion et al., 2000; Lobmaier et al., 2008; Harris and Aguirre, 2010; Meng et al., 2012), could facilitate face recognition in the right FFA through reciprocal connections, especially when faces are disrupted in their structural content, as was the case in our study.

More generally, the results of our functional connectivity analysis provide further support that measuring resting-state connectivity is a useful tool for investigating behaviorally relevant functional interaction between visual cortical areas (Zhu et al., 2011; Wang et al., 2013; O’Neil et al., 2014). It has recently been shown that the strength of the intrinsic functional connectivity within the occipitotemporal face network predicts perceptual ability to process faces depending on stimulus/task properties. For example, it was demonstrated that the connectivity of the FFA with the OFA (Zhu et al., 2011) and with the perirhinal cortex (O'Neil et al., 2014) is closely related to the behavioral face-inversion effect. Together with the present results, these findings suggest that processing of facial features takes place via coordinated interaction within the visual cortical face network, relying on synchronized spontaneous neural activity between face-processing regions.

To conclude, these results imply that perception of facial identity in the case of noisy face images is subserved by neural computations within the right FFA as well as a re-entrant processing loop involving bilateral FFA and LOC.

\section{References}

Baird LM, Burton AM (2008) The bilateral advantage for famous faces: interhemispheric communication or competition? Neuropsychologia 46: 1581-1587. CrossRef Medline

Bankó ÉM, Gál V, Körtvélyes J, Kovács G, Vidnyánszky Z (2011) Dissociating the effect of noise on sensory processing and overall decision difficulty. J Neurosci 31:2663-2674. CrossRef Medline

Bankó ÉM, Körtvélyes J, Weiss B, Vidnyánszky Z (2013) How the visual cortex handles stimulus noise: insights from amblyopia. PLoS One 8:e66583. CrossRef Medline

Biswal B, Yetkin FZ, Haughton VM, Hyde JS (1995) Functional connectivity in the motor cortex of resting human brain using echo-planar MRI. Magn Reson Med 34:537-541. CrossRef Medline

Brainard DH (1997) The Psychophysics Toolbox. Spat Vis 10:433-436. CrossRef Medline

Cauchoix M, Barragan-Jason G, Serre T, Barbeau EJ (2014) The neural dynamics of face detection in the wild revealed by MVPA. J Neurosci 34: 846-854. CrossRef Medline

Clark VP, Parasuraman R, Keil K, Kulansky R, Fannon S, Maisog JM, Ungerleider LG, Haxby JV (1997) Selective attention to face identity and color studied with fMRI. Hum Brain Mapp 5:293-297. CrossRef Medline

Cordes D, Haughton VM, Arfanakis K, Carew JD, Turski PA, Moritz CH, Quigley MA, Meyerand ME (2001) Frequencies contributing to functional connectivity in the cerebral cortex in "resting-state" data. Am J Neuroradiol 22:1326-1333. Medline
Crouzet SM, Kirchner H, Thorpe SJ (2010) Fast saccades toward faces: face detection in just $100 \mathrm{~ms}$. J Vis 10(4):16.1-17. CrossRef Medline

Dakin SC, Hess RF, Ledgeway T, Achtman RL (2002) What causes nonmonotonic tuning of fMRI response to noisy images? Curr Biol 12:R476R477; author reply R478. CrossRef Medline

Davies-Thompson J, Andrews TJ (2012) Intra- and interhemispheric connectivity between face-selective regions in the human brain. J Neurophysiol 108:3087-3095. CrossRef Medline

DiCarlo JJ, Cox DD (2007) Untangling invariant object recognition. Trends Cogn Sci 11:333-341. CrossRef Medline

Epstein RA, Higgins JS, Parker W, Aguirre GK, Cooperman S (2006) Cortical correlates of face and scene inversion: a comparison. Neuropsychologia 44:1145-1158. CrossRef Medline

Fox MD, Raichle ME (2007) Spontaneous fluctuations in brain activity observed with functional magnetic resonance imaging. Nat Rev Neurosci 8:700-711. CrossRef Medline

Fox MD, Snyder AZ, Vincent JL, Corbetta M, Van Essen DC, Raichle ME (2005) The human brain is intrinsically organized into dynamic, anticorrelated functional networks. Proc Natl Acad Sci U S A 102:9673-9678. CrossRef Medline

Furl N, Garrido L, Dolan RJ, Driver J, Duchaine B (2011) Fusiform gyrus face selectivity relates to individual differences in facial recognition ability. J Cogn Neurosci 23:1723-1740. CrossRef Medline

Geusebroek J-M, Burghouts GJ, Smeulders AWM (2005) The Amsterdam Library of Object Images. Int J Comput Vis 61:103-112. CrossRef

Gilaie-Dotan S, Gelbard-Sagiv H, Malach R (2010) Perceptual shape sensitivity to upright and inverted faces is reflected in neuronal adaptation. Neuroimage 50:383-395. CrossRef Medline

Goffaux V, Peters J, Haubrechts J, Schiltz C, Jansma B, Goebel R (2011) From coarse to fine? Spatial and temporal dynamics of cortical face processing. Cereb Cortex 21:467-476. CrossRef Medline

Grill-Spector K, Weiner KS (2014) The functional architecture of the ventral temporal cortex and its role in categorization. Nat Rev Neurosci 15: 536-548. CrossRef Medline

Grill-Spector K, Kushnir T, Hendler T, Edelman S, Itzchak Y, Malach R (1998) A sequence of object-processing stages revealed by fMRI in the human occipital lobe. Hum Brain Mapp 6:316-328. CrossRef Medline

Grill-Spector K, Kourtzi Z, Kanwisher N (2001) The lateral occipital complex and its role in object recognition. Vision Res 41:1409-1422. CrossRef Medline

Grill-Spector K, Knouf N, Kanwisher N (2004) The fusiform face area subserves face perception, not generic within-category identification. Nat Neurosci 7:555-562. CrossRef Medline

Harris A, Aguirre GK (2010) Neural tuning for face wholes and parts in human fusiform gyrus revealed by fMRI adaptation. J Neurophysiol 104: 336-345. CrossRef Medline

Hasson U, Harel M, Levy I, Malach R (2003) Large-scale mirror-symmetry organization of human occipito-temporal object areas. Neuron 37:10271041. CrossRef Medline

Haxby JV, Hoffman EA, Gobbini MI (2000) The distributed human neural system for face perception. Trends Cogn Sci 4:223-233. CrossRef Medline

Heekeren HR, Marrett S, Bandettini PA, Ungerleider LG (2004) A general mechanism for perceptual decision-making in the human brain. Nature 431:859-862. CrossRef Medline

Hegdé J (2008) Time course of visual perception: coarse-to-fine processing and beyond. Prog Neurobiol 84:405-439. CrossRef Medline

Hochstein S, Ahissar M (2002) View from the top: hierarchies and reverse hierarchies in the visual system. Neuron 36:791-804. CrossRef Medline

Horovitz SG, Rossion B, Skudlarski P, Gore JC (2004) Parametric design and correlational analyses help integrating fMRI and electrophysiological data during face processing. Neuroimage 22:1587-1595. CrossRef Medline

Huang L, Song Y, Li J, Zhen Z, Yang Z, Liu J (2014) Individual differences in cortical face selectivity predict behavioral performance in face recognition. Front Hum Neurosci 8:483. CrossRef Medline

Jiang F, Dricot L, Weber J, Righi G, Tarr MJ, Goebel R, Rossion B (2011) Face categorization in visual scenes may start in a higher order area of the right fusiform gyrus: evidence from dynamic visual stimulation in neuroimaging. J Neurophysiol 106:2720-2736. CrossRef Medline

Kanwisher N, McDermott J, Chun MM (1997) The fusiform face area: a module in human extrastriate cortex specialized for face perception. J Neurosci 17:4302-4311. Medline 
Kayser AS, Erickson DT, Buchsbaum BR, D’Esposito M (2010) Neural representations of relevant and irrelevant features in perceptual decision making. J Neurosci 30:15778-15789. CrossRef Medline

Larsson J, Heeger DJ (2006) Two retinotopic visual areas in human lateral occipital cortex. J Neurosci 26:13128-13142. CrossRef Medline

Lerner Y, Hendler T, Ben-Bashat D, Harel M, Malach R (2001) A hierarchi$\mathrm{cal}$ axis of object processing stages in the human visual cortex. Cereb Cortex 11:287-297. CrossRef Medline

Lewis MB, Edmonds AJ (2003) Face detection: mapping human performance. Perception 32:903-920. CrossRef Medline

Liu J, Harris A, Kanwisher N (2002) Stages of processing in face perception: an MEG study. Nat Neurosci 5:910-916. CrossRef Medline

Lobmaier JS, Klaver P, Loenneker T, Martin E, Mast FW (2008) Featural and configural face processing strategies: evidence from a functional magnetic resonance imaging study: Neuroreport 19:287-291. CrossRef

Malach R, Reppas JB, Benson RR, Kwong KK, Jiang H, Kennedy WA, Ledden PJ, Brady TJ, Rosen BR, Tootell RB (1995) Object-related activity revealed by functional magnetic resonance imaging in human occipital cortex. Proc Natl Acad Sci U S A 92:8135-8139. CrossRef Medline

Mazziotta J, Toga A, Evans A, Fox P, Lancaster J, Zilles K, Woods R, Paus T, Simpson G, Pike B, Holmes C, Collins L, Thompson P, MacDonald D, Iacoboni M, Schormann T, Amunts K, Palomero-Gallagher N, Geyer S, Parsons L, et al. (2001a) A probabilistic atlas and reference system for the human brain: International Consortium for Brain Mapping (ICBM). Philos Trans R Soc Lond B Biol Sci 356:1293-1322. CrossRef Medline

Mazziotta J, Toga A, Evans A, Fox P, Lancaster J, Zilles K, Woods R, Paus T, Simpson G, Pike B, Holmes C, Collins L, Thompson P, MacDonald D, Iacoboni M, Schormann T, Amunts K, Palomero-Gallagher N, Geyer S, Parsons L, et al. (2001b) A four-dimensional probabilistic atlas of the human brain. J Am Med Inform Assoc 8:401-430. CrossRef Medline

Mazziotta JC, Toga AW, Evans A, Fox P, Lancaster J (1995) A probabilistic atlas of the human brain: theory and rationale for its development. The International Consortium for Brain Mapping (ICBM). Neuroimage 2:89-101. CrossRef Medline

McCarthy G, Puce A, Gore JC, Allison T (1997) Face-specific processing in the human fusiform gyrus. J Cogn Neurosci 9:605-610. CrossRef Medline

Meng M, Cherian T, Singal G, Sinha P (2012) Lateralization of face processing in the human brain. Proc Biol Sci 279:2052-2061. CrossRef Medline

Minnebusch DA, Suchan B, Köster O, Daum I (2009) A bilateral occipitotemporal network mediates face perception. Behav Brain Res 198:179185. CrossRef Medline

Mohr B, Landgrebe A, Schweinberger SR (2002) Interhemispheric cooperation for familiar but not unfamiliar face processing. Neuropsychologia 40:1841-1848. CrossRef Medline

O'Craven KM, Downing PE, Kanwisher N (1999) fMRI evidence for objects as the units of attentional selection. Nature 401:584-587. CrossRef Medline

O’Neil EB, Hutchison RM, McLean DA, Köhler S (2014) Resting-state fMRI reveals functional connectivity between face-selective perirhinal cortex and the fusiform face area related to face inversion. Neuroimage 92:349355. CrossRef Medline

Pelli DG (1997) The VideoToolbox software for visual psychophysics: transforming numbers into movies. Spat Vis 10:437-442. CrossRef Medline

Pernet CR, Wilcox R, Rousselet GA (2012) Robust correlation analyses: false positive and power validation using a new open source MATLAB toolbox. Front Psychol 3:606. CrossRef Medline

Pinsk MA, Arcaro M, Weiner KS, Kalkus JF, Inati SJ, Gross CG, Kastner S (2009) Neural representations of faces and body parts in macaque and human cortex: a comparative fMRI study. J Neurophysiol 101:2581-2600. CrossRef Medline

Pitcher D, Duchaine B, Walsh V, Kanwisher N (2010) TMS evidence for feedforward and feedback mechanisms of face and body perception. J Vis 10(7):671. CrossRef

Pitcher D, Duchaine B, Walsh V, Yovel G, Kanwisher N (2011a) The role of lateral occipital face and object areas in the face inversion effect. Neuropsychologia 49:3448-3453. CrossRef Medline

Pitcher D, Walsh V, Duchaine B (2011b) The role of the occipital face area in the cortical face perception network. Exp Brain Res 209:481-493. CrossRef Medline

Rainer G, Augath M, Trinath T, Logothetis NK (2001) Nonmonotonic noise tuning of BOLD fMRI signal to natural images in the visual cortex of the anesthetized monkey. Curr Biol 11:846-854. CrossRef Medline

Rainer G, Augath M, Trinath T, Logothetis NK (2002) The effect of image scrambling on visual cortical BOLD activity in the anesthetized monkey. Neuroimage 16:607-616. CrossRef Medline

Reddy L, Moradi F, Koch C (2007) Top-down biases win against focal attention in the fusiform face area. Neuroimage 38:730-739. CrossRef Medline

Reinholz J, Pollmann S (2007) Neural basis of redundancy effects in visual object categorization. Neurosci Lett 412:123-128. CrossRef Medline

Righart R, Andersson F, Schwartz S, Mayer E, Vuilleumier P (2010) Topdown activation of fusiform cortex without seeing faces in prosopagnosia. Cereb Cortex 20:1878-1890. CrossRef Medline

Rossion B (2008) Constraining the cortical face network by neuroimaging studies of acquired prosopagnosia. Neuroimage 40:423-426. CrossRef Medline

Rossion B, Dricot L, Devolder A, Bodart JM, Crommelinck M, De Gelder B, Zoontjes R (2000) Hemispheric asymmetries for whole-based and partbased face processing in the human fusiform gyrus. J Cogn Neurosci 12:793-802. CrossRef Medline

Rossion B, Caldara R, Seghier M, Schuller AM, Lazeyras F, Mayer E (2003) A network of occipito-temporal face-sensitive areas besides the right middle fusiform gyrus is necessary for normal face processing. Brain 126:23812395. CrossRef Medline

Rossion B, Hanseeuw B, Dricot L (2012) Defining face perception areas in the human brain: a large-scale factorial fMRI face localizer analysis. Brain Cogn 79:138-157. CrossRef Medline

Rotshtein P, Geng JJ, Driver J, Dolan RJ (2007a) Role of features and second-order spatial-relations in face discrimination, face recognition, and individual face skills. J Cogn Neurosci 19:1435-1452. CrossRef Medline

Rotshtein P, Vuilleumier P, Winston J, Driver J, Dolan R (2007b) Distinct and convergent visual processing of high and low spatial frequency information in faces. Cereb Cortex 17:2713-2724. CrossRef Medline

Rousselet GA, Macé MJ, Fabre-Thorpe M (2003) Is it an animal? Is it a human face? Fast processing in upright and inverted natural scenes. J Vis 3(6):440-455. CrossRef Medline

Schweinberger SR, Baird LM, Blümler M, Kaufmann JM, Mohr B (2003) Interhemispheric cooperation for face recognition but not for affective facial expressions. Neuropsychologia 41:407-414. CrossRef Medline

Silson EH, McKeefry DJ, Rodgers J, Gouws AD, Hymers M, Morland AB (2013) Specialized and independent processing of orientation and shape in visual field maps LO1 and LO2. Nat Neurosci 16:267-269. CrossRef Medline

Steeves J, Dricot L, Goltz HC, Sorger B, Peters J, Milner AD, Goodale MA, Goebel R, Rossion B (2009) Abnormal face identity coding in the middle fusiform gyrus of two brain-damaged prosopagnosic patients. Neuropsychologia 47:2584-2592. CrossRef Medline

Tang H, Buia C, Madhavan R, Crone NE, Madsen JR, Anderson WS, Kreiman G (2014) Spatiotemporal dynamics underlying object completion in human ventral visual cortex. Neuron 83:736-748. CrossRef Medline

Tiddeman B, Burt M, Perrett D (2001) Prototyping and transforming facial textures for perception research. IEEE Comput Graph Appl 21:42-50. CrossRef

Tjan BS, Lestou V, Kourtzi Z (2006) Uncertainty and Invariance in the Human Visual Cortex. J Neurophysiol 96:1556-1568. CrossRef Medline

Tzourio-Mazoyer N, Landeau B, Papathanassiou D, Crivello F, Etard O, Delcroix N, Mazoyer B, Joliot M (2002) Automated anatomical labeling of activations in SPM using a macroscopic anatomical parcellation of the MNI MRI single-subject brain. Neuroimage 15:273-289. CrossRef Medline

Wang X, Han Z, He Y, Caramazza A, Song L, Bi Y (2013) Where color rests: spontaneous brain activity of bilateral fusiform and lingual regions predicts object color knowledge performance. Neuroimage 76:252-263. CrossRef Medline

Weiner KS, Grill-Spector K (2010) Sparsely-distributed organization of face and limb activations in human ventral temporal cortex. Neuroimage 52: 1559-1573. CrossRef Medline

Weiner KS, Sayres R, Vinberg J, Grill-Spector K (2010) fMRI-adaptation and category selectivity in human ventral temporal cortex: regional differences across time scales. J Neurophysiol 103:3349-3365. CrossRef Medline 
Weissenbacher A, Kasess C, Gerstl F, Lanzenberger R, Moser E, Windischberger C (2009) Correlations and anticorrelations in resting-state functional connectivity MRI: A quantitative comparison of preprocessing strategies. Neuroimage 47:1408-1416. CrossRef Medline

Wojciulik E, Kanwisher N, Driver J (1998) Covert visual attention modulates face-specific activity in the human fusiform gyrus: fMRI study. J Neurophysiol 79:1574-1578. Medline

Xia M, Wang J, He Y (2013) BrainNet Viewer: a network visualization tool for human brain connectomics. PLoS One 8:e68910. CrossRef Medline

Yovel G, Kanwisher N (2004) Face perception: domain specific, not process specific. Neuron 44:889-898. CrossRef Medline

Yovel G, Kanwisher N (2005) The neural basis of the behavioral faceinversion effect. Curr Biol 15:2256-2262. CrossRef Medline

Yovel G, Tambini A, Brandman T (2008) The asymmetry of the fusiform face area is a stable individual characteristic that underlies the left-visualfield superiority for faces. Neuropsychologia 46:3061-3068. CrossRef Medline

Zhang H, Tian J, Liu J, Li J, Lee K (2009) Intrinsically organized network for face perception during the resting state. Neurosci Lett 454:1-5. CrossRef Medline

Zhang J, Li X, Song Y, Liu J (2012) The fusiform face area is engaged in holistic, not parts-based, representation of faces. PLoS One 7:e40390. CrossRef Medline

Zhen Z, Fang H, Liu J (2013) The hierarchical brain network for face recognition. PLoS One 8:e59886. CrossRef Medline

Zhu Q, Zhang J, Luo YL, Dilks DD, Liu J (2011) Resting-state neural activity across face-selective cortical regions is behaviorally relevant. J Neurosci 31:10323-10330. CrossRef Medline 